$\mathcal{B} \mathcal{T} \mathcal{P} \mathcal{S}$

Brazilian Transportation

Planning Society
Journal of Transport Literature

Vol. 6, n. 4, pp. 228-234, Oct 2012

Reviews \& Essays
JTL | RELIT

www.transport-literature.org ISSN 2238-1031

\title{
Proteção e liberalização no transporte marítimo de cabotagem: o uso da regulação nos mercados canadense e brasileiro
}

[Protection and liberalization in cabotage transportation system: the regulation use in Canadian and Brazilian markets]

\author{
Marcus Vinícius Nascimento*
}

Instituto Tecnológico de Aeronáutica (ITA), Brazil

Submitted 20 Sep 2011; received in revised form 18 Dec 2011; accepted 26 Jan 2012

\begin{abstract}
Resumo
0 transporte marítimo de cabotagem, representado pela movimentação de mercadorias ao longo da costa marítima, tem demonstrado significante competitividade em relação a outros modais, principalmente pelo seu baixo custo de frete. 0 objetivo deste trabalho é apresentar o que a literatura traz sobre a regulação deste modal e desenvolver uma comparação entre o cenário canadense e o brasileiro. Nota-se que, no Canadá, o sistema passa por problemas de eficiência produtiva, principalmente pelo curto prazo de permanência permitido aos containeres estrangeiros no país. Em contraposição ao Canadá, a extensa costa e as altas taxas de importação, contribuem com o desenvolvimento deste modal no Brasil. Todavia, as políticas do Mercosul impedem a cabotagem de longo curso para os outros países da mesma costa (i.e. Argentina), fato que facilitaria as trocas comerciais entre os países.
\end{abstract}

Palavras-Chave: transporte; regulação; cabotagem.

\begin{abstract}
The maritime cabotage, represented by the movement of goods along the coastline, has shown as a competitive modal against other transportation systems, especially because of its low cost freight. The objective of this paper is to present what the literature brings about the cabotage regulation and to develop a comparison between Canadian and Brazilian markets. In a first analysis, the Canadian's system goes through problems of productivity efficiency, especially for the short stayed permitted time of foreign containers in the country. In a contrast, the extensive coastline and the high import taxes, contribute to the development of Brazilian cabotage. However, the policies of Mercosur prevent the cabotage along countries in the same coast (i.e. Brasil-Argentina), a fact that would facilitate trade between the countries.

Key words: transportation; regulation; cabotage.
\end{abstract}

* Corresponding Author. Email: mvn.marcus@gmail.com.

\section{Recommended Citation}

Nascimento, M. V. (2012) Proteção e liberalização no transporte marítimo de cabotagem: o uso da regulação nos mercados canadense e brasileiro. Journal of Transport Literature, vol. 6, n. 4, pp. 228-234.

JTL/RELIT is a fully electronic, peer-reviewed, open access, international journal focused on emerging transport markets and published by BPTS - Brazilian Transport Planning Society. Website www.transport-literature.org. ISSN 2238-1031. 


\section{Introdução}

O transporte marítimo de cabotagem refere-se à movimentação de mercadorias ao longo das margens da costa litorânea e pela navegação interior (rios). Subdivide-se entre cabotagem de pequeno e longo curso, sendo que a primeira refere-se às movimentações dentro do país e a segunda ao transporte de mercadorias para países diferentes, mas pertencentes à mesma costa continental (i.e. Brasil-Argentina). De acordo com Borges (2005), um dos fatores de maior competitividade do modal é o seu valor de frete. Em média, o frete da cabotagem no Brasil é de $\mathrm{R} \$ 40$ por tonelada a cada $1000 \mathrm{~km}$, enquanto o frete ferroviário é de $\mathrm{R} \$ 65,00$ e o rodoviário alcança os $\mathrm{R} \$ 100,00$.

Nos países da América do Norte e em diversos outros do continente Asiático, a regulação do mercado de cabotagem volta-se para as questões de segurança, tributação e legislação social. Kosior et. al (2009), apresentam possíveis ganhos de eficiência produtiva através da redução nos gastos de combustível, nas distâncias totais percorridas e na emissão de poluentes no serviço marítimo de cabotagem canadense caso houvesse uma readequação das medidas regulatórias tomadas pelo governo.

Com base neste cenário, o presente trabalho tem o objetivo de desenvolver um estudo comparativo entre o transporte de cabotagem canadense e o brasileiro no que tange às questões regulatórias do sistema.

Para atingir satisfatoriamente o objetivo proposto, o trabalho final é dividido em três seções. A primeira seção refere-se ao levantamento da literatura necessária para embasar conceitualmente o tema. Será implementada uma pesquisa da literatura recente sobre a cabotagem marítima e como é abordado o uso da regulação deste mercado em países específicos. A segunda seção destina-se em apresentar um estudo comparativo e algumas das tendências quanto aos cenários canadense e brasileiro sobre a regulação do sistema de cabotagem. A terceira seção é voltada para as discussões finais e a conclusão do trabalho. 


\section{Análise da Literatura Recente sobre a Regulação do Transporte Marítimo de Cabotagem}

Conforme levantado por Kosior et. al (2009), existem evidências globais sobre as reformas regulatórias no transporte de cabotagem. Uma das primeiras iniciativas para a regulamentação deste mercado está contida no ato governamental norte-americano Jones Act de 1920. De acordo com Brooks et. al (2004), com intuito de proteger a indústria naval nacional, a criação do ato determina que a construção das embarcações utilizadas na cabotagem deve ser constituída nos EUA e que o serviço é, necessariamente, regido por uma empresa com bandeira nacional. Além disso, constata-se a exigência de que $75 \%$ dos tripulantes da frota de qualquer embarcação de cabotagem seja composta por norte-americanos.

Em um outro cenário, Kosior et. al (2009) apresenta que, mesmo possuindo uma costa litorânea com $67000 \mathrm{~km}$ navegáveis, o continente europeu chegou a ter queda na ordem de $37 \%$ no mercado de cabotagem marítima, entre meados da década de 1980 e o final da década de 1990. Este fato, explicado pelas altas tributações, pode ser fruto das dificuldades em se consolidar uma regulação adequada que contemplasse as peculiaridades dos países componentes da União Europeia.

O capítulo seguinte, volta-se aos mercados canadense e brasileiro. Ambos os países, apresentam características distintas no sistema de cabotagem, principalmente no que tange à forma de transporte das mercadorias.

\section{Tendências observadas nos mercados Canadense e Brasileiro}

\subsection{Regulação do Transporte Marítimo de Cabotagem Canadense}

A cabotagem marítima no Canadá é regulamentada pelo Canadian Customs Regulations. Conforme explorado por Barbosa (2008), um dos principais objetivos deste conjunto de regulamentações é o desenvolvimento da navegação nacional sem expô-la à competição internacional. Entretanto, fatores como a falta de capacitação e os atrasos tecnológicos dos estaleiros, tornam-se um entrave para o desenvolvimento do mercado no país. Constata-se 
ainda, que a formação do Customs Regulations é constituída por vários membros e associações públicos e privados, os quais, nem sempre, possuem interesses em comum.

Assumindo o pressuposto anterior, pode-se afirmar que o mercado canadense enfrenta dificuldades em relação à competitividade no transporte de cabotagem, algo que tende a influenciar negativamente as políticas de preço praticadas pelos transportadores e torna o sistema inábil à concorrer com outras formas de modais.

À adicionar a baixa eficiência na construção naval, Kosior et. al (2009) consideram que apesar da obrigatoriedade das embarcações serem produzidas no país, a maior parte containeres utilizados no transporte interno são fabricados na China. Evidencia-se, neste fato, que as regulamentações canadenses não possuem um efetivo efeito protecionista do mercado interno.

Um outro ponto a ser considerado, são os prazos de permanência dos containeres estrangeiros no país. Diferente do que ocorre nos Estados Unidos (Jones Act), onde a permanência é liberada por até 365 dias, Vido et. al (2001) elucidam que pelo anexo MEMO D3-7-1 do Customs Tariff 9801.10, a permanência máxima dos contêineres estrangeiros é de seis meses.

Por fim, Kosior et. al (2009) desenvolvem diversos cenários para otimizar a produtividade do transporte marítimo de cabotagem canadense. O uso colaborativo de embarcações para a movimentação de mercadorias de importação e domésticas, além do desenvolvimento de novas rotas impactariam positivamente a redução de emissões de gases poluentes e o tempo de percurso das embarcações. Contudo, as regulamentações nacionais inibem estas aplicações.

\subsection{Cabotagem: O Caso Brasileiro}

Diferente do que ocorre no Canadá, a regulação da cabotagem no Brasil é realizada pelo órgão governamental ANTAQ - Agência Nacional de Transporte Aquaviário. De acordo com Capraro (2008), além de regular o transporte marítimo no país, a ANTAQ possui o objetivo de supervisionar e fiscalizar as atividades marítimas.

Segundo a ANTAQ (apud Fadda, 2007), 24 empresas nacionais são capacitadas e liberadas à realizarem o serviço de cabotagem. Apesar deste número não parecer expressivo, Fadda (2007) apresenta um crescimento médio de $29 \%$ ao ano, do sistema, desde 1997. Desta forma, 
a cabotagem representava $18 \%$ de todos os movimentos internos de mercadorias em 2006 , no país.

Outra grande diferença entre a cabotagem brasileira e a canadense, é o tipo de mercadoria transportada. Conforme a Tabela 1, nota-se que, em 2005, o granel líquido dominava os movimentos da cabotagem nacional, com uma curva de crescimento ascendente, até aquele momento.

\begin{tabular}{|c|c|c|}
\hline Tipo de Mercadoria & $\begin{array}{c}\text { Quantidade Aproximada } \\
\text { (Milhões de Toneladas) }\end{array}$ & Representação \% \\
\hline $\begin{array}{c}\text { Granel Líquido } \\
\text { (petróleo e derivados) }\end{array}$ & 118 & $78 \%$ \\
\hline Granel Sólido & 28 & $16 \%$ \\
\hline Carga Geral & 10 & $6 \%$ \\
\hline TOTAL & 156 & $100 \%$ \\
\hline
\end{tabular}

Tabela 1 - Matriz Brasileira: Mercadorias movimentadas pela cabotagem marítima ao final de 2005 Fonte: Borges (2005), adaptada

Somado à impulsão gerada pelo transporte de petróleo, Pinto et. al (2007) considera que as políticas de redução das taxas de juros cobradas pela Marinha Mercante e os altos impostos de importação, também contribuíram com o expressivo aumento do market share da cabotagem nacional frente os outros modais.

Todavia, uma das preocupações dos operadores marítimos nacionais são as barreiras para a cabotagem em longo curso. Moura e Botter (2011), levantam a hipótese de ganhos no transporte de carne entre Argentina e Brasil através da cabotagem. Entretanto, os acordos bilaterais entre os países deparam-se com barreiras políticas impostas pela proposta de desenvolvimento conjunto do Mercosul, ou seja, se não é possível ao Brasil fazer a cabotagem até o Chile, por exemplo, o Mercosul impede que seja feita a cabotagem para qualquer outra localidade na qual a cabotagem seria geograficamente viável. 


\section{Conclusões}

Os recentes dados sobre o transporte marítimo de cabotagem o coloca em uma posição de alta competitividade em relação aos outros modais. No Brasil, o valor médio de frete chega a ser $40 \%$ mais barato do que o transporte rodoviário em um trecho de mesma distância. Além disso, a impulsão dada pelo transporte de granel líquido, principalmente os derivados de petróleo, fizeram com que a cabotagem detivesse $18 \%$ de todos os movimentos internos de mercadorias no país no ano de 2006.

A preocupação dos países em proteger o desenvolvimento marítimo através da regulação é evidente e um dos marcos é a criação do Jones Act em 1920, nos Estados Unidos. Entretanto, países como o Canadá, tem passado por dificuldades em adaptar a regulação do modal em relação às condições e necessidades locais. Algumas pesquisas desenvolvem estratégias que procuram o aumento da eficiência da cabotagem no país, todavia, ao se depararem com uma regulação inadequada, os possíveis ganhos competitivos encontram uma barreira impeditiva que gera efeitos para toda a cadeia produtiva.

Desta forma, torna-se necessário reavaliar as ações regulamentadoras para tornar a cabotagem marítima mais competitiva em relação aos outros modais de transporte. Fica então, o desafio às agências reguladoras de flexibilizar e adaptar as regulações. Por outro lado, ainda existe um abrangente campo de estudo sobre a cabotagem marítima. Sendo que as novas pesquisas podem buscar um melhor entendimento sobre o deste modal e, a partir deste ponto, propor novas melhorias.

\section{Referências}

Barbosa, M. M. R. C. (2008) A Expansão da Cabotagem e os Reflexos na Gestão da Cadeia Logística dos Usuários de Transporte. $9^{\circ}$ Conferência Nacional de Portos, São Paulo.

Bertoloto, R. F. e Mello, J. C. C. B. S. (2011) Eficiência de portos e terminais privativos brasileiros com características distintas. Journal of Transport Literature, vol. 5, n. 2, pp. 4-21.

Borges, C. (2005) A Influência da Logística na Economia Brasileira. Intermodal South America.

Brooks, M. R., Frost, J. D. (2004) Short Sea Shipping: A Canadian Perspective. Maritime Policy Management.

Capraro, M. C. Z. (2008) Aspectos Destacados da Regulação Econômica da Cabotagem no Brasil. III Congresso Iberoamericano de Regulação Econômica. 
Collyer, W. O. (2013) A importância do direito marítimo e da regulação dos transportes e portos para o desenvolvimento da logística. Journal of Transport Literature, Vol. 7, n.1.

Fadda, E. A. (2007) Considerações sobre o Transporte Marítimo de Cabotagem no Brasil. XX Copinaval - Congresso Panamericano de Engenharia Naval, Transporte Marítimo e Engenharia Portuária, São Paulo.

Falcão, V. A. and Correia, A. R. (2012) Eficiência portuária: análise das principais metodologias para o caso dos portos brasileiros. Journal of Transport Literature, Vol. 6, n.4.

Kosior, J., Vido, E., Prentice, B. E. (2009) Creating Lean, Green and Agile Supply Chains: the Benefits of Cabotage Liberalization. Canadian Journal of Transportation, Vol. 3, Part. 1.

Moura, D. A., Botter, R. C. (2011) O Transporte por Cabotagem no Brasil - Potencialidade para a Intermodalidade Visando a Melhoria do Fluxo Logístico. Revista Produção Online. Florianópolis, SC, v.11, n. 2, p. 595-617.

Pinto, M. M. O., Colin, E. C., Favarin, J. V. R., Akao, D. R. P. L., Aderson, V. L. (2007) Legislação de Cabotagem no Brasil: Oportunidades e entraves para a Indústria de Construção Naval. XX Copinaval - Congresso Panamericano de Engenharia Naval, Transporte Marítimo e Engenharia Portuária, São Paulo.

Santos, J. T. A. N., Cardoso, P. e Moita, M. H. V. (2011) Atributos de Paralisação como Indicador de Produtividade da Operação Portuária de Cabotagem em Manaus. Journal of Transport Literature, vol. 5, n. 4, pp. 70-87.

Vido, E., Kosior, J. (2001) An assessment of North American Cabotage Laws: the carriage of goods in marine containers. Canadian Transportation Research Forum. 